\title{
Use of hamster as a model to study diet-induced atherosclerosis
}

\author{
Alice Dillard", Nirupa R Matthan, Alice H Lichtenstein
}

\begin{abstract}
Golden-Syrian hamsters have been used as an animal model to assess diet-induced atherosclerosis since the early 1980s. Advantages appeared to include a low rate of endogenous cholesterol synthesis, receptor-mediated uptake of LDL cholesterol, cholesteryl ester transfer protein activity, hepatic apoB-100 and intestinal apoB-48 secretion, and uptake of the majority of LDL cholesterol via the LDL receptor pathway. Early work suggested hamsters fed high cholesterol and saturated fat diets responded similarly to humans in terms of lipoprotein metabolism and aortic lesion morphology. Recent work has not consistently replicated these findings. Reviewed was the literature related to controlled hamster feeding studies that assessed the effect of strain, background diet (non-purified, semipurified) and dietary perturbation (cholesterol and/or fat) on plasma lipoprotein profiles and atherosclerotic lesion formation. F1B hamsters fed a non-purified cholesterol/fat-supplemented diet had more atherogenic lipoprotein profiles ( $\mathrm{nHDL}-\mathrm{C}>\mathrm{HDL}-\mathrm{C}$ ) than other hamster strains or hamsters fed cholesterol/fat-supplemented semi-purified diets. However, fat type; saturated (SFA), monounsaturated or n-6 polyunsaturated (PUFA) had less of an effect on plasma lipoprotein concentrations. Cholesterol- and fish oil-supplemented semi-purified diets yielded highly variable results when compared to SFA or n-6 PUFA, which were antithetical to responses observed in humans. Dietary cholesterol and fat resulted in inconsistent effects on aortic lipid accumulation. No hamster strain was reported to consistently develop lesions regardless of background diet, dietary cholesterol or dietary fat type amount. In conclusion, at this time the Golden-Syrian hamster does not appear to be a useful model to determine the mechanism(s) of diet-induced development of atherosclerotic lesions.
\end{abstract}

\section{Introduction}

Cardiovascular disease (CVD) is the leading cause of mortality in developed countries and is a growing health challenge in developing countries [1,2]. The majority of CVD is attributed to atherosclerosis, characterized by endothelial dysfunction, chronic inflammation, dyslipidemia, and accumulation of lipid in arterial walls [1,3-10]. Data from both observational and interventional studies indicate that dietary modification can alter atherosclerotic lesion progression $[5,11,12]$. Although the diet/CVD relationship was first identified at the turn of the $20^{\text {th }}$ century [13], salient issues related to dietary fat type are still in question [14-16].

Randomized controlled human intervention trials in the field of diet and CVD are rare, in part due to the complexity and cost of executing the studies, limited

\footnotetext{
* Correspondence: alice.dillard_hirschel@tufts.edu Cardiovascular Nutrition Laboratory, Jean Mayer U.S. Department of Agriculture, Human Nutrition Research Center on Aging at Tufts University, 711 Washington Street, Boston, MA 02111, USA
}

number of validated surrogate biomarkers to track disease progression, and inaccessibility of pivotal tissues/ organs necessary to determine underlying mechanisms. The availability of an animal model addresses the later issue by allowing the assessment of diet and atherosclerosis development in multiple tissue systems simultaneously. This in turn facilitates a more complete understanding of the complex relationship between diet and CVD risk. In general, unmodified rats and mice are not suitable animal models to study diet-induced changes in plasma lipid and lipoprotein concentrations and atherosclerotic lesion development because they do not develop aortic lesions or an atherogenic lipoprotein profile [non-high-density lipoprotein cholesterol (nHDLC) > high-density lipoprotein cholesterol (HDL-C)] similar to that observed in humans. Transgenic, knock-out, and knock-down mouse models have been used successfully to study discrete components of the system [17-21], but it is difficult to use these models to assess
C Biomed Central

(c) 2010 Dillard et al; licensee BioMed Central Ltd. This is an Open Access article distributed under the terms of the Creative Commons Attribution License (http://creativecommons.org/licenses/by/2.0), which permits unrestricted use, distribution, and reproduction in any medium, provided the original work is properly cited. 
Table 1 Golden-Syrian hamsters fed cholesterol and SFA-supplemented non-purified diets compared to chow

\begin{tabular}{|c|c|c|c|c|c|c|c|c|c|c|c|c|c|c|c|}
\hline & & & & & & & & Chow & $\begin{array}{l}\mathrm{mg} / \\
\mathrm{dL}\end{array}$ & & & SFA & $\begin{array}{c}\mathrm{mg} / \\
\mathrm{dL}\end{array}$ & & \\
\hline Ref & Strain & $\begin{array}{c}\text { Age } \\
\text { (weeks) }\end{array}$ & $\begin{array}{c}\text { Study } \\
\text { Length } \\
\text { (weeks) }\end{array}$ & $\begin{array}{l}\% \text { Fat } \\
(w / w)\end{array}$ & $\begin{array}{l}\% \mathrm{CH} \\
(w / w)\end{array}$ & $\begin{array}{l}\text { HDL- } \\
\text { C }\end{array}$ & $\begin{array}{l}\text { nHDL- } \\
\text { C }\end{array}$ & $\begin{array}{c}\text { nHDL-C: } \\
\text { HDL-C }\end{array}$ & TG & $\begin{array}{l}\text { HDL- } \\
\text { C }\end{array}$ & $\begin{array}{c}\text { nHDL- } \\
\text { C }\end{array}$ & $\begin{array}{l}\text { nHDL-C: } \\
\text { HDL-C }\end{array}$ & TG & Lesion & Lesion Measure \\
\hline [38] & F1B & 8 & 5 & $10^{1}$ & 0.05 & & & & 150 & & & & 650 & $\uparrow$ & Aorta stained $\left(\mu^{2}\right)$ \\
\hline$[31]$ & F1B & 8 & 8 & $10^{2}$ & 0.05 & 58 & 58 & 1.0 & 87 & 88 & 234 & 2.7 & 216 & $\uparrow$ & $\begin{array}{l}\text { Foam cells } / \mathrm{mm}^{2} \\
\text { aorta }\end{array}$ \\
\hline$[55]$ & F1B & 8 & 12 & $10^{3}$ & 0.1 & 48 & 35 & 0.7 & 110 & 67 & 444 & 6.6 & 545 & $\leftrightarrow$ & $\begin{array}{l}\text { CE (ug)/aorta (mg } \\
\text { wet weight) }\end{array}$ \\
\hline [55] & $C R$ & 8 & 12 & $10^{3}$ & 0.1 & 68 & 67 & 1.0 & 129 & 86 & 210 & 2.4 & 195 & $\uparrow$ & $\begin{array}{l}\text { CE (ug)/aorta (mg } \\
\text { wet weight) }\end{array}$ \\
\hline [49] & $C R$ & 10 & 24 & $5^{3}$ & 2 & 50 & 47 & 0.9 & 186 & 247 & 581 & 2.4 & 1912 & $\uparrow$ & $\begin{array}{l}\text { Fatty streak area } \\
(\%)\end{array}$ \\
\hline [47] & $C R$ & 8 & 6 & $10^{2}$ & 0.1 & 71 & 25 & 0.4 & 219 & 108 & 112 & 1.0 & 341 & $\leftrightarrow$ & $\begin{array}{l}\text { Aorta with lesion } \\
(\%)\end{array}$ \\
\hline$[47]$ & $C R$ & 8 & 6 & $10^{3}$ & 0.1 & 71 & 25 & 0.4 & 219 & 108 & 174 & 1.6 & 301 & $\leftrightarrow$ & $\begin{array}{l}\text { Aorta with lesion } \\
(\%)\end{array}$ \\
\hline$[58]$ & UNK & $3-4$ & 28 & $5^{3}$ & 1 & & & & 120 & & & & 169 & $\leftrightarrow$ & $\begin{array}{l}\text { EC (ug)/aorta } \\
\text { (10mg dry } \\
\text { weight) }\end{array}$ \\
\hline$[50]$ & UNK & 5 & 40 & $10^{2}$ & 0.3 & 87 & 64 & 0.7 & 102 & 153 & 224 & 1.5 & 295 & $\uparrow \uparrow$ & $\begin{array}{l}\text { Fatty streak area } \\
\text { (\%) }\end{array}$ \\
\hline
\end{tabular}

SFA: saturated fatty acid; CH: cholesterol; HDL-C: high-density lipoprotein cholesterol; nHDL-C: non-HDL-C; TG: triglycerides; CR: Charles River; UNK: unknown hamster strain; EC: esterified cholesterol. SFA source: ${ }^{1}$ Hydrogenated coconut oil, ${ }^{2}$ Coconut oil and ${ }^{3}$ Butter

multi-component etiologies. Such questions are best investigated using unmodified animal models.

Since the 1980s hamsters have been used as an animal model to assess diet-induced atherosclerosis [22]. Relative to other unmodified rodent models, the hamster was thought to be preferable due to its apparent low rate of endogenous cholesterol synthesis, receptormediated uptake of low density lipoprotein cholesterol, presence of cholesteryl ester transfer protein (CETP) activity [23-28], secretion of apolipoprotein (apo) B-100 from the liver and apo B-48 from the small intestine [29], and uptake of the majority of LDL-C via the LDL receptor pathway [22]. The morphology of aortic foam cells and lesions in hamsters fed atherogenic diets was reported to be similar to human lesions [22,30,31].

More recent work has not consistently replicated the plasma lipoprotein response or aortic lesion morphology in hamsters that was previously shown to be similar to humans [31-43]. Our aim was to review the literature regarding diet interventions in Golden-Syrian hamsters, and plasma lipid and lipoprotein response and aortic lesion formation.

\section{Methods}

\section{Literature Search Strategy and Data Extraction}

A literature search was conducted through January, 2010 in PubMed. The following search terms were used: dietary cholesterol, dietary fat, and fatty acids. These terms were crossed with hamster. Then the terms atherosclerosis and plasma lipoprotein were searched independently and then crossed with hamster. Finally, the results from the two searches were crossed. The search was limited to English language publications. To ensure completeness this method was supplemented by reviewing citations in recent publications. Extracted data included intervention period, male hamster strain, male hamster age, background diet, and diet composition. For the later point emphasis was placed on dietary cholesterol amount, and dietary fat type and amount.

\section{Results}

\section{Outcome Measures}

\section{Plasma lipid and lipoproteins}

Studies that reported plasma cholesterol (total cholesterol, HDL-C and nHDL-C) and/or plasma triglyceride (TG) concentrations were included in the data summaries. All plasma lipids were measured after hamsters were food deprived.

\section{Aortic lesion development}

In general, two approaches have been used to measure aortic lesions. The first method was oil red-O lipid staining. These data were expressed using multiple systems; $\mu \mathrm{m}^{2}$ fatty streak $/ \mathrm{mm}^{2}$ aorta $[31,35,36,44-46]$, percent total aortic lesion area $[47,48]$, percent aortic arch fatty streak area [49-51], percent foam cell area [52] or aortic cross-sections as percent total "internal elastic 
lamina" [30]. The use of multiple reporting systems made cross comparisons among studies challenging. The second method was determining aortic cholesteryl ester (CE) content. The data tended to be either expressed as either CE/mg aortic wet weight [37,39,53-57] or dry weight [58]. Oil red-O staining provided a measure of lesion surface area, but no data on the nature and invasiveness of the lesion. CE content provided an assessment of total aortic cholesterol accumulation, but did not provide an indication of the lesion type.

\section{Covariates}

Intervention period, hamster strain and sex, background diet and diet composition, including amount of cholesterol and type and amount of fat, were found to affect outcome measures.

\section{Intervention Periods}

Intervention periods ranged from 3 weeks $[59,60]$ to 12 months [22,61]. The most common intervention periods ranged from 10 and 12 weeks [33-35,37,42, $43,46,48,51,53-56,62-66]$. Outcome measures for the shorter term studies ( $<6$ weeks) were primarily plasma lipoprotein profiles and for the mid- to long-term studies (6-12 weeks) was aortic lesion formation.

\section{Hamster Strain}

Four Golden-Syrian hamster strains have been predominantly used to study diet-induced atherosclerosis. These strains can be characterized as being derived from inbred or outbred hamsters. In common usage, the one inbred strain was the F1B hamster from Biobreeders (Watertown, MA). The three outbred strains were Charles River (CR) (Wilmington, MA), Sasco (Omaha, $\mathrm{NE})$ and Harlan (Indianapolis, IN).

\section{Hamster Sex}

The vast majority of studies used male hamsters only (115 out of 120). Seven studies included female hamsters [38,43,67-71]. Of those, three studies reported on fetal cholesterol metabolism only [69-71], two studies compared plasma lipoprotein concentrations or atherosclerotic lesion development between female ovariectomized and sham-operated hamsters $[67,68]$, and two studies compared plasma lipoprotein concentrations and atherosclerotic lesion development between male and female hamsters $[38,43]$. Due to the limited amount of data and lack of comparable data, outcome measures for female hamsters were not included.

\section{Background Diet}

Two distinct types of background diets have been used for hamster studies: semi-purified and non-refined. Semi-purified diets were composed of refined ingredients such as casein and sucrose, whereas non-purified diets were composed of unmodified ingredients such as grains and grain products. A standard vitamin and mineral mix was added to both [72]. Semi-purified diets were generally favored because they provide more uniformity and reproducibility.

\section{Diet Composition}

Dietary Cholesterol Studies designed to asses dietinduced changes in plasma lipids or atherosclerosis, for the most part, include supplemental cholesterol. The levels used in most hamster studies exceed what was considered high intake in humans. The amount of cholesterol was of concern because large amounts $(\geq 1 \% \mathrm{w} /$ $\mathrm{w})$ were hepatotoxic; impairing normal lipoprotein metabolism [30,55,73]. Hepatotoxicity has been characterized by visual inspection of the liver or measuring hepatic cholesterol content, hepatic lipoprotein metabolism and apolipoprotein synthesis $[23,25,55]$. The amount of supplemental dietary cholesterol identified ranged from 0 to $3 \%(\mathrm{w} / \mathrm{w})[22,30,64,74]$. The majority of studies have used between 0.05 to $0.2 \%$ cholesterol (w/w) [30-36,39,40,42,43,46-48,51-56,59,62,63,66,75-94].

Dietary Fat Studies feeding hamsters diets supplemented fat were examined to determine if fatty acid chain length and degree of unsaturation alter plasma lipids or aortic lesion development.

Dietary Fat Type

The amount of supplemental dietary fat has ranged from 0 to $20 \%(\mathrm{w} / \mathrm{w})[30,32,36,48,51,62,76$ $78,85,90,95-97$ ], with $10 \%$ (w/w) used most frequently $[31,33-35,37-43,45,47,50,52-56,59,63,65,66,79-84,88,92,9-$ $4,98,99]$. Ten percent saturated fatty acids (SFA) with supplemental cholesterol has been consistently reported to raise plasma total cholesterol and nHDL-C concentrations $[31,38,47,50,55,62]$ without having adverse effects on hepatic function [51]. The most commonly used sources of SFA were coconut oil [31-35,39-44,47, $50,52,54,56,59,61,63,66,80,83,84,86,88,94,99,100]$, fullyhydrogenated coconut oil $[32,38,48,62,78,82]$ and butter $[22,30,47,49,51,53,55,57,58,85,101,102]$. Comparison fats were either monounsaturated fatty acids (MUFA) or omega- 6 polyunsaturated fatty acids ( $n-6$ PUFA). The most commonly used source of MUFA were canola $[44,47,53]$ and olive $[37,56,76,98]$ oils, and n-6 PUFA were soybean $[47,53,94]$, safflower $[56,102]$ and sunflower $[37,45,46]$ oils. The most commonly used source of very long chain omega-3 PUFA ( $n-3$ PUFA) was fish oil $[95,96,102-104]$.

\section{Data Presentation}

Due to the nature of the data identified it was presented within subsections; plasma lipids and lipoproteins, and aortic lesion. Within each subsection, the data were presented by hamster strain, background diet, dietary cholesterol and dietary fat type. The figures are a visual representation summarizing the data extracted. They are one approach to represent the range of findings. Observations discussed in the plasma lipid and lipoprotein 


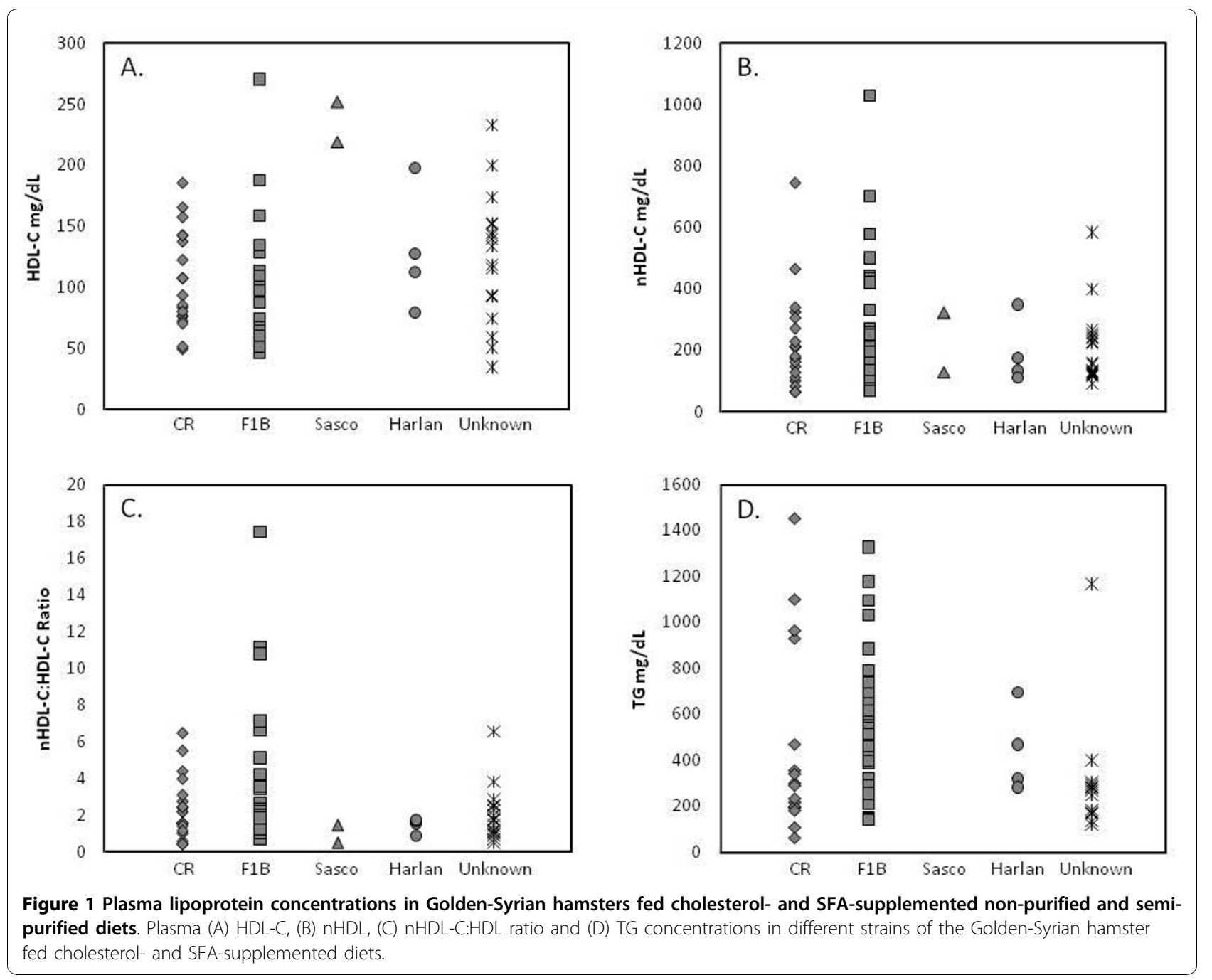

and aortic lesion subsections were made on the basis of visual assessments rather than statistical analysis which was precluded due to the heterogeneous nature of the data in terms of study designs, dietary perturbations and hamster strains.

\section{Plasma Lipid and Lipoproteins Hamster Strain}

In response to cholesterol- and SFA-supplemented diets, the inbred F1B [28,31-33,35,39,41-44,54-56,59,61-63, $77,80,86,94,96,98,100,105]$ hamster has been more consistently reported to develop an atherogenic lipoprotein profile (nHDL-C > HDL-C) than any of the three outbred strains, CR $[28,34,36,40,47-49,53,55,66$, $84,88,94,99,102,106]$, Sasco [30,51] and Harlan $[28,85,107]$ hamsters (Figure $1 \mathrm{~A}-\mathrm{C})$. In the outbred strains, in contrast to that normally observed in humans, the HDL-C concentrations were equal to or slightly higher than nHDL-C concentrations. Noteworthy was the wide range of plasma cholesterol concentrations after the hamsters were fed a cholesterol- and SFA-supplemented diet, regardless of strain (Figure 1A-C) $[22,24,28,30-36,38-44,47-59,61-64,66,75,77,78,80-86,88$, $89,92,94,96,98-100,105-114]$

Inbred and outbred hamster strains exhibited a wide range of plasma TG concentrations, with the F1B hamsters exhibiting the widest absolute range (119 to 1350 $\mathrm{mg} / \mathrm{dL})[28,31,33,35,38,39,41-44,52,54-56,59,62,63,77,80$, $86,94,96,98,100,105]$ (Figure 1D). The hypertriglyceridemia in the inbred and outbred hamster strains fed cholesterol- and SFA-supplemented diet appeared to be inconsistent with the response in humans, which tended to be null or increased slightly $[115,116]$.

Age at initiation of dietary intervention did not show a clear pattern with regard to plasma lipoprotein concentrations and ranged from 2 to 28 weeks. Of note, over half of F1B hamsters started a study at 8 weeks of age. Amount of dietary cholesterol and amount and type of 
dietary fat could partially explain the wide range of plasma lipoprotein concentrations reported and will be discussed in subsequent sections. Because the majority of data available relate to the F1B hamster the subsequent discussion will be limited to that strain; however, data for all the strains was summarized in supplementary tables and figures.

\section{Background Diet}

F1B hamsters fed non-purified diets supplemented with cholesterol and SFA [22,31,33-36,38-44,47,48,50,52,53, $55,58,59,61,63,64,66,80,82,84-86,88,98-100,105-107,114]$ resulted in lower HDL-C (Figure $2 \mathrm{~A}$ ) and higher nHDL$\mathrm{C}$ concentrations (Figure $2 \mathrm{~B}$ ) than the same strain fed a semi-purified diet supplemented with cholesterol and SFA $[30,32,46,51,54,56,62,75,77,78,81,83,89,92,94,102$, $108-110,112,113]$. Of note, the resulting nHDL-C:HDL$\mathrm{C}$ ratios were higher in the majority of studies using non-purified, but not semi-purified diets (Figure 2C). No notable difference in response to the two background diets in plasma TG concentrations was observed (Figure 2D) [31,33-49,52-56,59,62,63,66,76,77,80,84-86, 88,94-96,98, 100-102,107].

With respect to differences identified in plasma lipoprotein concentrations resulting from the two background diets, potential differences in fiber and/or other non-essential dietary components, such as phytochemicals, between the non-purified and semi-purified diets could account for the differences. No data addressing this variable was identified.

\section{Diet Composition}

Dietary Cholesterol In the absence of supplemental dietary fat, the higher the dietary cholesterol, the higher the resulting nHDL-C concentrations $[53,73,87,117,118]$. Hamsters fed a non-purified diet supplemented with $1 \%$ $(\mathrm{w} / \mathrm{w})$ cholesterol resulted in higher nHDL-C concentrations [117] compared to hamsters fed similar diets containing less cholesterol $[0.1-0.2 \%(\mathrm{w} / \mathrm{w})][53,73,87,118]$. Cholesterol added to semi-purified diets ranging from $0.1-0.3 \%(\mathrm{w} / \mathrm{w})$ without supplemental fat resulted in similar nHDL-C concentrations [79,82,91,119,120]. There were no studies in hamsters fed semi-purified diets with greater than $0.3 \%(\mathrm{w} / \mathrm{w})$ cholesterol in the absence of supplemental fat.

Compared to cholesterol-supplemented semi-purified diets $[79,82,91,119]$, supplementing non-purified diets $[53,87,117,118]$ with cholesterol, in the absence of supplemental fat, was reported to result in similar nHDL-C concentrations (Additional file 1Figure S1B). Noteworthy, cholesterol-supplemented semi-purified diets $[79,82,91,119]$ without supplemental fat consistently resulted in higher HDL-C concentrations compared to non-purified diets $[53,87,117,118]$ (Additional file 1Figure S1A).

\section{Dietary Fat}

SFA, MUFA and n-6 PUFA In response to cholesteroland SFA-, MUFA- or n-6 PUFA-supplemented diets, HDL-C concentrations were higher, nHDL-C:HDL-C ratio were lower, and $\mathrm{nHDL}-\mathrm{C}$ and TG concentrations were similar in F1B hamsters fed semi-purified diets compared to non-purified diets (Figure 3A-D) $[28,44,46,56,94,98,105]$. However, there were no differences in plasma lipoprotein concentrations among fat types in hamsters fed either non-purified or semi-purified diets (Figure 3A-D).

Of note was the trend of a positive relationship between HDL-C and TG concentrations in F1B hamsters fed semi-purified diets regardless of fat type (Figure 3A\&3D). This response was in contrast to humans, who tend to exhibit an inverse relationship between the two lipoprotein fractions [121].

Very Long Chain n-3 PUFA Notable was an anomaly in the F1B hamster with regard to fish oil (very long chain n-3 fatty acid) and plasma lipoprotein response. In humans, fish oil has little effect on plasma cholesterol concentrations [122]. Similarly, in F1B hamsters fed fish oil-supplemented semi-purified diets without cholesterol there was little effect on plasma cholesterol concentrations (data not shown) $[96,104]$. However, when cholesterol was included in the diet, the response was highly variable and in some cases resulted in extreme elevations in nHDL-C concentrations (Figure 4A-C) $[56,96,102,104]$. Similar data using non-purified diets supplemented with fish oil were unavailable.

In hypertriglyceridemic patients, high intakes (35 grams/day) of very long chain $n-3$ fatty acids decreased plasma TG concentrations [123]. In contrast, hamsters fed cholesterol- and fish oil-supplemented semi-purified diets plasma TG concentrations increased 1 - to 5-fold compared to cholesterol- and SFA- or n-6 PUFA-supplemented semi-purified diets (Figure 4D) $[95,96,103]$. When data were available for other hamster strains this trend was not observed (Additional file 2Figure S2).

\section{Aortic Lesion \\ Hamster Strain}

In response to cholesterol- and SFA-supplemented diets, three studies reported that F1B $[31,38,100]$ and CR $[22,49,55]$ and one unknown strain of hamster [50] responded with an increase in lesion lipid or foam cell formation compared to chow fed hamsters (Table 1). In contrast, one study in F1B [55], one study in CR [47] and one in an unknown strain [58] reported no lesion development compared to chow (Table 1). The only aortic lesion development data reported for Sasco hamsters compared diets supplemented with cholesterol 
Table 2 Aortic lesion development in F1B Golden-Syrian hamsters fed supplemented non-purified and semi-purified diets

\begin{tabular}{cccccccc}
\hline Ref & Strain & \% Fat $(\mathbf{w} / \mathbf{w})$ & \% CH $(\mathbf{w} / \mathbf{w})$ & Diet $\mathbf{1}$ & Diet $\mathbf{2}$ & Outcome & Outcome Variable \\
\hline$[39]$ & F1B & $10^{2}$ & 0.1 & CO & CLA & $\leftrightarrow$ & CE (ug)/aorta (mg) \\
\hline$[39]$ & F1B & $10^{2}$ & 0.1 & CO & LA & $\leftrightarrow$ & CE (ug)/aorta (mg) \\
\hline$[39]$ & F1B & $10^{2}$ & 0.1 & CO & CLA + LA & $\leftrightarrow$ & CE (ug)/aorta (mg) \\
\hline$[105]$ & F1B & $10^{2}$ & 0.15 & CO & Safflower Oil & $\leftrightarrow$ & CE (ug)/aorta (mg) \\
\hline$[54]$ & F1B & $10^{3}$ & 0.1 & Palm Oil/CO & Macademia Oil & $\leftrightarrow$ & CE (ug)/aorta (mg) \\
\hline$[54]$ & F1B & $10^{3}$ & 0.1 & Palm Oil/CO & Canola Oil & $\leftrightarrow$ & CE (ug)/aorta (mg) \\
\hline$[54]$ & F1B & $10^{3}$ & 0.1 & Palm Oil/CO & Safflower Oil & $\leftrightarrow$ & CE (ug)/aorta (mg) \\
\hline$[54]$ & F1B & $10^{3}$ & 0.1 & Macademia Oil & Canola Oil & $\leftrightarrow$ & CE (ug)/aorta (mg) \\
\hline$[54]$ & F1B & $10^{3}$ & 0.1 & Macademia Oil & Safflower Oil & $\leftrightarrow$ & CE (ug)/aorta (mg) \\
\hline$[54]$ & F1B & $10^{3}$ & 0.1 & Canola Oil & Safflower Oil & $\leftrightarrow$ & CE (ug)/aorta (mg) \\
\hline$[56]$ & F1B & $10^{3}$ & 0.1 & CO & Olive Oil & $\leftrightarrow$ & CE (ug)/aorta (mg) \\
\hline$[56]$ & F1B & $10^{3}$ & 0.1 & CO & Safflower Oil & $\leftrightarrow$ & CE (ug)/aorta (mg) \\
\hline$[56]$ & F1B & $10^{3}$ & 0.1 & Olive Oil & Safflower Oil & $\leftrightarrow$ & CE (ug)/aorta (mg) \\
\hline$[105]$ & F1B & $10^{3}$ & 0.15 & CO & Safflower Oil & $\leftrightarrow$ & CE (ug)/aorta (mg) \\
\hline & F1B & $10^{3}$ & 0.1 & CO & Fish Oil & $\leftrightarrow$ & CE (ug)/aorta (mg) \\
\hline F1B & $10^{3}$ & 0.1 & Olive Oil & Fish Oil & $\leftrightarrow$ & CE (ug)/aorta (mg) \\
\hline F1B & $10^{3}$ & 0.1 & Safflower Oil & Fish Oil & $\leftrightarrow$ & CE (ug)/aorta (mg) \\
\hline
\end{tabular}

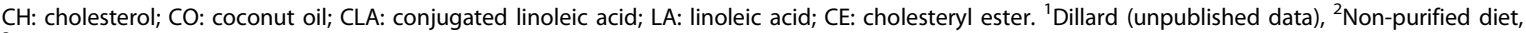

${ }^{3}$ Semi-Purified diet

and SFA, with no comparison to chow or an unsupplemented diet $[30,51]$. No studies were identified that reported data on the development of aortic lesions in Harlan hamsters. The method used to characterize aortic lesion development, age at initiation of dietary intervention, and length of dietary intervention was different among studies, making cross comparisons difficult to interpret (Table 1).

\section{Background Diet}

Despite differences in the plasma lipoprotein profile, the dearth of data precluded an assessment of whether background diet onto which the cholesterol and SFA was superimposed altered aortic lesion development.

\section{Diet Composition}

Dietary Cholesterol Only two studies were identified that reported the effect of dietary cholesterol on aortic lesion development. Dietary cholesterol at 0.12 and $0.2 \%$ $(\mathrm{w} / \mathrm{w})$ added to a semi-purified diet in the absence of supplemental fat increased stained aortic lesion area compared to a non-supplemented semi-purified diet $[46,91]$. Similar data using non-purified diets were unavailable.

As noted with the plasma lipoprotein response, a wide range in degree of aortic lesion development was noted after the hamsters were fed a cholesterol- and SFAsupplemented diet, regardless of strain (Table 1) $[31,38,47,49,50,55,58]$.
Dietary Fat Five studies were identified that contained data on aortic lesion development in F1B hamsters in response to different types of dietary fat. Regardless of background diet or supplemental cholesterol, no differences were observed in response to dietary fat type $[39,54,56,105]$ (Table 2). The multiple methods used to assess aortic lesion formation did not appear to impact the outcomes reported. Considering the data from all the hamster strains simultaneously did not alter this conclusion (Additional file 3: Table S1). However, 2 out of 8 studies reported a larger fatty streak area in cholesterol- and SFA-supplemented non-purified diets compared to cholesterol- and MUFA-supplemented nonpurified diets $[36,64]$. When comparing stained fatty streak area between cholesterol- and MUFA- or n-6 PUFA-supplemented hamsters, the latter group exhibited more lesion [45] and aortic CE accumulation [37].

\section{Conclusion}

Early work suggested that hamsters fed diets supplemented with cholesterol and SFA were a useful animal model to study diet induced atherosclerosis. Hamsters appeared to respond to a cholesterol- and SFA-supplemented diet by increasing nHDL-C, ultimately leading to enhanced deposition of cholesterol in the aorta and increased atherosclerotic lesion development. More recent data were less consistent on the usefulness of the model. 

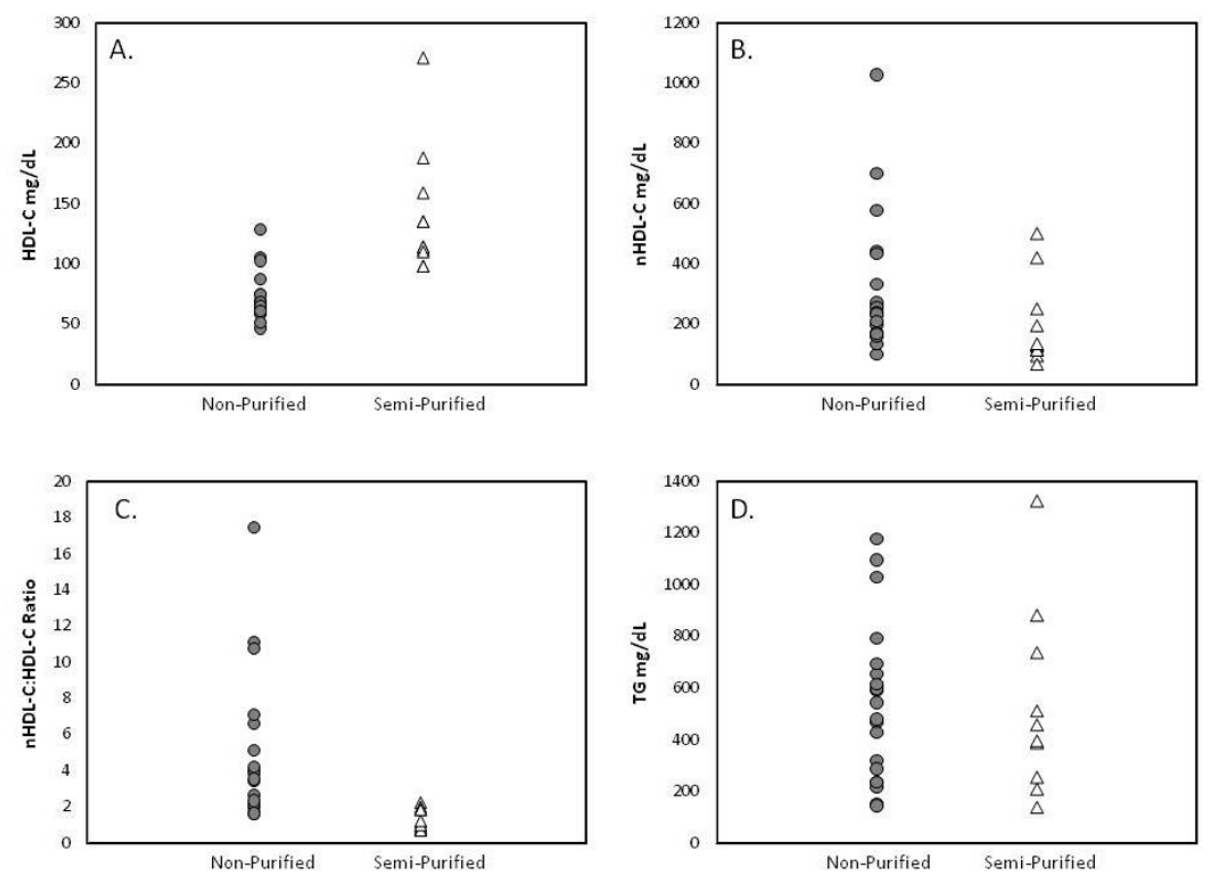

Figure 2 Plasma lipoprotein concentrations in F1B hamsters fed cholesterol- and SFA-supplemented non-purified or semi-purified diets. Plasma (A) HDL-C, (B) nHDL, (C) nHDL-C:HDL ratio and (D) TG concentrations in F1B hamsters fed cholesterol- and SFA-supplemented non-purified or semi-purified diets.
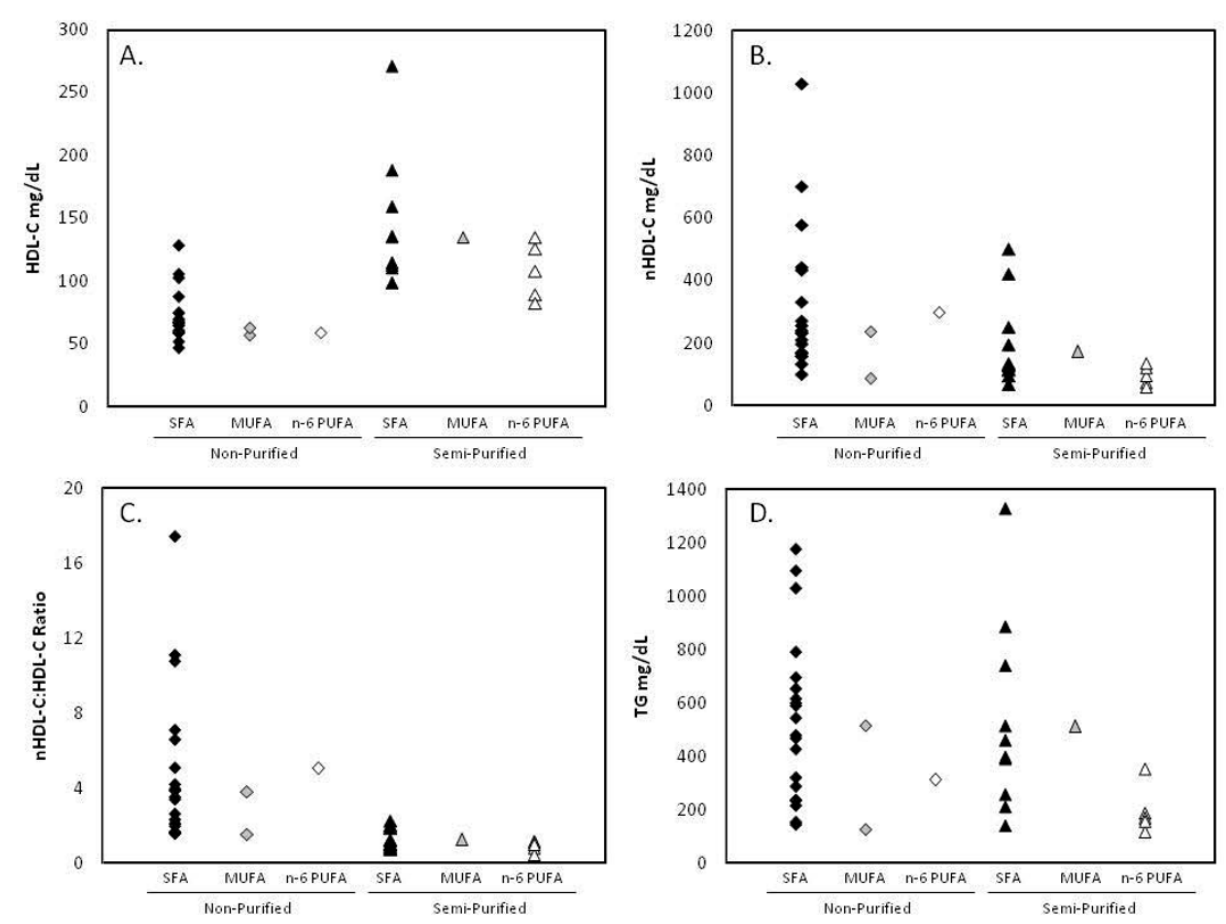

Figure 3 Plasma lipoprotein concentrations in F1B hamsters fed cholesterol- and SFA-, MUFA, or n-6 PUFA-supplemented diets. Plasma (A) HDL-C, (B) nHDL, (C) nHDL-C:HDL ratio and (D) TG concentrations in F1B hamsters fed cholesterol- and SFA-, MUFA- or n-6 PUFAsupplemented non-purified or semi-purified diets. 


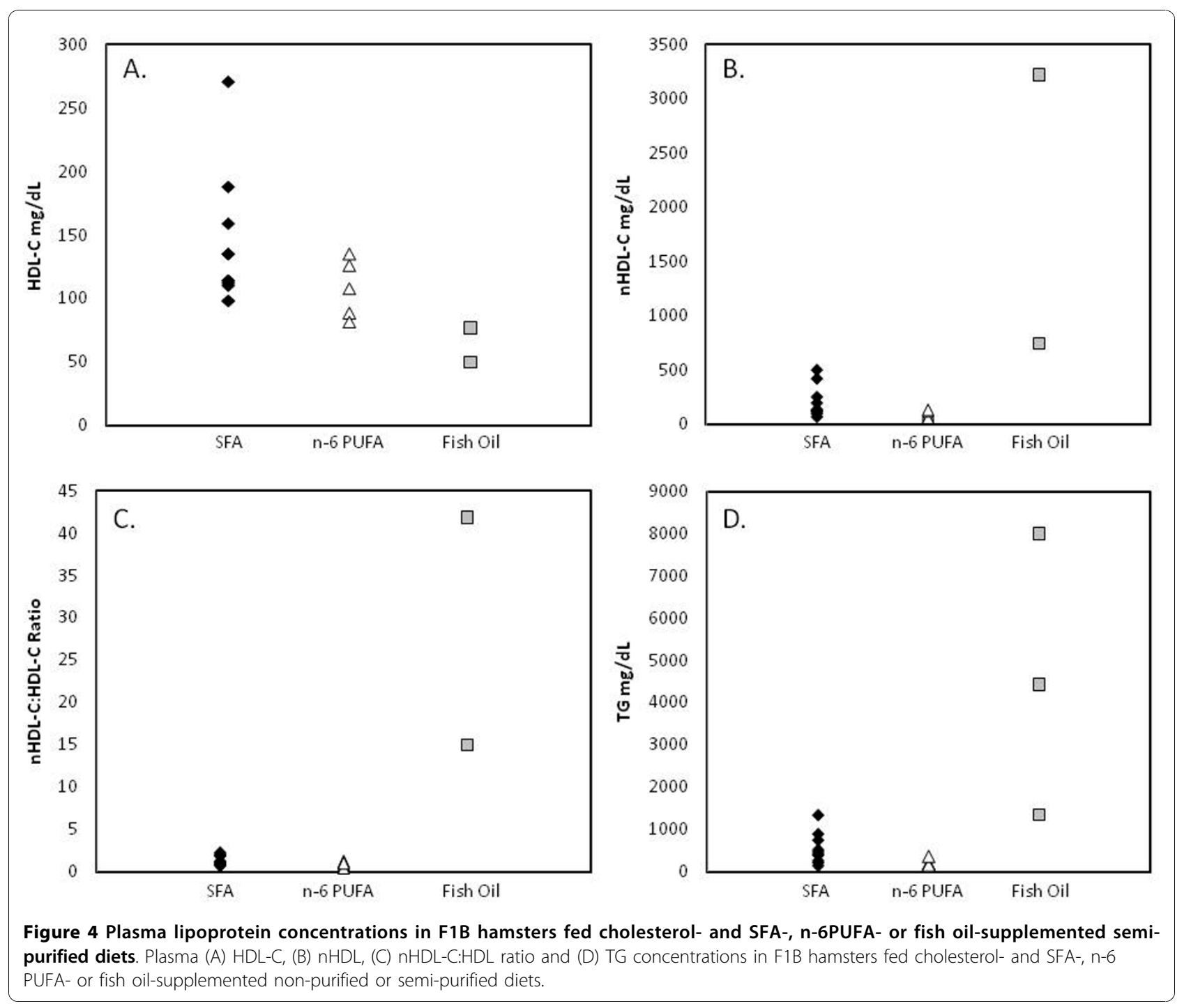

The data showed a relatively consistent response of the F1B hamsters fed cholesterol- and SFA-supplemented diets to develop an atherogenic lipoprotein profile (nHDL-C > HDL-C). For those studies in which aortic lesion data were also available, an atherogenic lipoprotein profile did not consistently result in lesion development. No hamster strain consistently developed aortic lesions regardless of atherogenic lipoprotein profile. Data relating other hamster strains to diet induced changes in lipoprotein profile or lesion development were too limited and inconsistent to draw conclusions.

On the basis of limited data, it appears that non-purified diets containing $0.1 \%$ to $0.2 \%(\mathrm{w} / \mathrm{w})$ dietary cholesterol were most commonly associated with eliciting an atherogenic lipoprotein profile without compromising hepatic function. There was insufficient data to determine the effect of dietary cholesterol alone on aortic lesion development. Potential hamster strain differences in response to dietary cholesterol could not be addressed in this review due to insufficient data.

In summary, F1B hamsters fed non-purified diets supplemented with cholesterol and SFA led to a more atherogenic lipoprotein profile compared to all other hamster strains as well as F1B hamsters fed similarly supplemented semi-purified diets. This would suggest that F1B hamsters fed a cholesteroland SFA-supplemented non-purified diet would be a good model in which to compare and contrast dietinduced changes in plasma lipoprotein concentrations. However, fat type including SFA, MUFA and n-6 PUFA had little effect on plasma lipoprotein concentrations. Cholesterol- and fish oil-supplemented semi-purified diets produced highly variable plasma lipoprotein responses and results antithetical to that observed in humans. 
Aortic lesion development in response to dietary fat type was inconsistent and inconclusive because no hamster strain repeatedly developed aortic lesions regardless of background diet, amount of dietary cholesterol, or amount and type of dietary fat.

On the basis of available data it does not appear at this time that the hamster is a useful model to determine the mechanisms underlying the development of diet-induced atherosclerosis. If this model were to be pursued it will be important to develop a standardized atherogenic diet and length of dietary intervention tailored to a specific hamster species, explore potential issues related to sex differences, and come to consensus for the analytical approaches most appropriate to assess the outcome measures of interest.

\section{List of Abbreviations}

Apo: apolipoprotein; CE: cholesteryl ester; CETP: cholesteryl ester transfer protein; CR: Charles River; CVD: cardiovascular disease; HDL-C: high density lipoprotein cholesterol; LDL: low density lipoprotein; MUFA:

monounsaturated fatty acids; nHDL-C: non-high density lipoprotein cholesterol; n-3 PUFA: omega-3 polyunsaturated fatty acids; n-6 PUFA: omega- 6 polyunsaturated fatty acids; PUFA: polyunsaturated fatty acids; SFA: saturated fatty acids; TG: triglyceride.

\section{Additional material}

Additional file 1: Plasma lipoprotein concentrations in hamsters fed cholesterol-supplemented non-purified or semi-purified diets. A set of 4 graphs of plasma lipoprotein concentrations representing studies that fed hamsters cholesterol-supplemented diets without additional fat.

Additional file 2: Plasma lipoprotein concentrations in hamsters fed cholesterol- and fat-supplemented non-purified or semi-purified diets. A set of 4 graphs of plasma lipoprotein concentrations representing studies that fed different strains of hamsters varying types of fat, including SFA, MUFA, n-6 PUFA and fish oil.

Additional file 3: Aortic lesion development in CR and unknown strains of Golden-Syrian hamsters fed supplemented non-purified diets. The file contains an additional table of studies that show aortic lesion development in CR and unknown strains of hamsters fed supplemented non-purified diets.

\section{Acknowledgements}

Supported by USDA agreement 588-1950-9-001. Any opinions, findings, conclusions or recommendations expressed in this publication are those of the author(s) and do not necessarily reflect the view of the USDA.

\section{Authors' contributions}

$A D, N R M$ and $A H L$ designed research, $A D$ conducted comprehensive review and analyzed data, $A H L$ provided essential materials, $A D$ and $A H L$ wrote the paper, and $A D, N R M$ and $A H L$ had primary responsibility for final content. All authors read and approved the final manuscript.

\section{Competing interests}

The authors declare that they have no competing interests.

Received: 7 October 2010 Accepted: 10 December 2010 Published: 10 December 2010
References

1. AHA: Heart Disease and Stroke Statistics - 2008 Update. 2008 [http:// www.americanheart.org/presenter.jhtml?identifier=3037327].

2. World Health Organization: Definition, diagnosis and classification of diabetes mellitus and its complications. Report of a WHO Consultation Part 1: Diagnosis and classification of Diabetes Mellitus Geneva: WHO; 1999.

3. Boudjeltia K, Guillaume M, Henuzet C: Fibrinolysis and cardiovascular risk factors: association with fibrinogen, lipids, and monocyte count. Eur $J$ Inter Med 2006, 17:102-108.

4. Danesh J, Lewington S, Thompson S, Collaboration FS: Plasma fibrinogen level and the risk of major cardiovascular diseases and nonvascular mortality. An individual participant meta-analysis. JAMA 2005, 294:1799-1809.

5. Expert Panel on Detection Evaluation and Treatment of High Blood Cholesterol in Adults (Adult Treatment Panel III): Executive summary of the third report of the National Cholesterol Education Program (NCEP). Journal of the American Medical Association 2001, 285:2486-2497.

6. Gatto N, Hodis H, Liu C-R: Brachial artery vasoreactivity is associated with cross-sectional and longitudinal anatomical measures of atherosclerosis in post-menopausal women with coronary artery disease. Atherosclerosis 2008, 196:674-681.

7. Ingelsson E, Pencina M, Tofler G: Multimarker approach to evaluate the incidence of the metabolic syndrome and longitudinal changes in metabolic risk factors. The Framingham Offspring Study. Circulation 2007, 116:984-992.

8. Libby $P$, Ridker $P$, Maseri A: Inflammation and atherosclerosis. Circulation 2002, 105:1135-1143.

9. Vakkilainen J, Steiner G, Ansauer J: Relationships between low density lipoprotein particle size, plasma lipoproteins, and progression of coronary artery disease: the Diabetes Atherosclerosis Intervention Study (DAIS). Circulation 2003, 107:1733-1737.

10. Wallace C, Newhouse S, Braund P, Zhang F: Genome-wide association study identifies genes for biomarkers of cardiovascular disease: serum urate and dyslipidemia. Am J Hum Genet 2008, 82:139-149.

11. Hu FB, Willett WC: Optimal diets for prevention of coronary heart disease. JAMA 2002, 288:2569-2578.

12. Lichtenstein $A H$, Appel $L$, Brands $M$, Carnethon M, Daniels S, Franch HA, Franklin B, Kris-Etherton P, Harris WS, Howard B, Karanja N, Lefevre M, Rudel L, Sacks F, Van Horn L, Winston M, Wylie-Rosett J: Diet and lifestyle recommendations revision 2006: a scientific statement from the American Heart Association Nutrition Committee. Circulation 2006, 114:82-96

13. Kritchevsky D: Dietary Protein, Cholesterol and Atherosclerosis: A Review of the Early History. J Nutr 1995, 125:589S-593S.

14. Mente A, de Koning L, Shannon HS, Anand SS: A systematic review of the evidence supporting a causal link between dietary factors and coronary heart disease. Archives of Internal Medicine 2009, 169:659-669.

15. Siri-Tarino PW, Sun Q, Hu F, Krauss R: Meta-analysis of prospective cohort studies evaluating the association of saturated fat with cardiovascular disease. American Journal of Clinical Nutrition 2010, 91:535-546.

16. Jakobsen MU, O'Reilly EJ, Heitmann BL, Pereira MA, Balter K, Fraser GE, Goldbourt U, Hallmans G, Knekt P, Liu S, Pietinen P, Spiegelman D, Stevens J, Virtamo J, Willett WC, Ascherio A: Major types of dietary fat and risk of coronary heart disease: a pooled analysis of 11 cohort studies. American Journal of Clinical Nutrition 2009, 89:1425-1432.

17. Vasandani C, Kafrouni A, Caronna A: Upregulation of hepatic LDL transport by $\mathrm{n}-3$ fatty acids in LDL receptor knockout mice. J Lipid Res 2002, 43:772-784.

18. Zadelaar S, Kleemann $\mathrm{R}$, Verschuren L: Mouse models for atherosclerosis and pharmaceutical modifiers. Arterioscler Thromb Vasc Biol 2007, 27:1706-1721.

19. Cyrus T, Sung S, Zhao L, Funk C, Tang S, Pratico D: Effect of low-dose aspirin on vascular inflammation, plaque stability, and atherogenesis in low-density lipoprotein receptor-deficient mice. Circulation 2002, 106:1282-1287.

20. Napoli C, Williams-Ignarro S, Nigris FD: Long-term combined beneficial effects of physical training and metabolic treatment on atherosclerosis in hypercholesterolemic mice. Proc Natl Acad Sci USA 2004, 101:8797-8802.

21. El-Sohemy A, Archer M: Effects of $n-3$ and $n-6$ polyunsaturated fatty acids on 3-hydroxy-3-methylglutaryl-CoA reductase in liver and mammary 
glands of low density lipoprotein-receptor knockout mice. Lipids 1999, 34(Suppl):S135.

22. Nistor A, Bulla A, Filip DA, Radu A: The hyperlipidemic hamster as a model of experimental atherosclerosis. Atherosclerosis 1987, 68:159-173.

23. Spady D, Dietschy J: Dietary saturated triacylglycerols suppress hepatic low density lipoprotein receptor activity in the hamster. Proc Natl Acad Sci USA 1985, 82:4526-4530.

24. Ahn YS, Smith D, Osada J, Li Z, Schaefer EJ, Ordovas JM: Dietary fat saturation affects apolipoprotein gene expression and high density lipoprotein size distribution in golden Syrian hamsters. Journal of Nutrition 1994, 124:2147-2155.

25. Chen J, Song W, Redinger RN: Effects of dietary cholesterol on hepatic production of lipids and lipoproteins in isolated hamster liver. Hepatology 1996, 24:423-434.

26. Remillard P, Shen G, Milne R, Maheux P: Induction of cholesteryl ester transfer protein in adipose tissue and plasma of the fructose-fed hamster. Life Science 2001, 69:677-687.

27. Quig DW, Arbeeny CM, Zilversmit DB: Effects of hyperlipidemias in hamster on lipid transfer protein activity and unidirectional cholesteryl ester transfer in plasma. Biochim biophys Acta 1991, 1093:257-264.

28. Trautwein EA, Liang J, Hayes KC: Cholesterol Gallstone Induction in Hamsters Reflects Strain Differences in Plasma Lipoproteins and Bile Acid Profiles. Lipids 1993, 28:305-312.

29. Liu G, Fan L, Redinger R: The association of hepatic apoprotein and lipid metabolism in hamsters and rats. Comp Biochem Physiol 1991, 99A:223-228.

30. Kahlon T, Chow F, Irving D, Sayre R: Cholesterol response and foam cell formation in hamsters fed two levels of saturated fat and various levels of cholesterol. Nutr Res 1996, 16:1353-1368.

31. Kowala MC, Nunnari JJ, Durham SK, Nicolosi RJ: Doxazosin and cholestyramine similarly decrease fatty streak formation in the aortic arch of hyperlipidemic hamsters. Atherosclerosis 1991, 91:35-49.

32. Delaney B, Nicolosi R, Wilson T, Carlson T, Frazer S, Zheng G-H, Hess R, Ostergren K, Haworth J, Knutson N: Beta-Glucan Fractions from Barley and Oats Are Similarly Antiatherogenic in Hypercholesterolemic Syrian Golden Hamsters. J Nutr 2003, 133:468-495.

33. El-Swefy S, Schaefer EJ, Seman LJ, van Dongen D, Sevanian A, Smith DE, Ordovas JM, El-Sweidy M, Meydani M: The effect of vitamin E, probucol, and lovastatin on oxidative status and aortic fatty lesions in hyperlipidemic-diabetic hamsters. Atherosclerosis 2000, 149:277-286.

34. Foxall TL, Shwaery GT, Stucchi AF, Nicolosi RJ, Wongt SS: Dose-related Effects of Doxazosin on Plasma Lipids and Aortic Fatty Streak Formation in the Hypercholesterolemic Hamster Model. Amer J Path 1992, 140:1357-1363.

35. Nicolosi RJ, Wilson TA, Krause BR: The ACAT inhibitor, Cl-1011 is effective in the prevention and regression of aortic fatty streak area in hamsters. Atherosclerosis 1998, 137:77-85.

36. Nicolosi RJ, Wilson TA, Rogers EJ, Kritchevsky D: Effects of specific fatty acids (8:0,14:0, cis-18:1, trans-18:1) on plasma lipoproteins, early atherogenic potential, and LDL oxidative properties in the hamster. $J$ Lipid Res 1998, 39:1972-1980.

37. Nicolosi RJ, Woolfrey B, Wilson TA, Scollin P, Handelman G, Fisher R: Decreased aortic early atherosclerosis and associated risk factors in hypercholesterolemic hamsters fed a high- or mid-oleic acid oil compared to a high-linoleic acid oil. J Nutr Biochem 2004, 15:540-547.

38. Robins S, Fasulo J, Patton G, Schaefer E, Smith D, Ordovas J: Gender Differences in the Development of Hyperlipemia and Atherosclerosis in Hybrid Hamsters. Metabolism 1995, 44:1326-1331.

39. Wilson T, Nicolosi R, Saati A, Kotyla T, Kritchevsky D: Conjugated Linoleic Acid Isomers Reduce Blood Cholesterol Levels but Not Aortic Cholesterol Accumulation in Hypercholesterolemic Hamsters. Lipids 2006, 41:41-48.

40. Wilson TA, Kritchevsky D, Kotyla T, Nicolosi RJ: Structured triglycerides containing caprylic (8:0) and oleic (18:1) fatty acids reduce blood cholesterol concentrations and aortic cholesterol accumulation in hamsters. Biochimica et Biophysica Acta 2006, 1761:345-349.

41. Wilson TA, Meservey CM, Nicolosi RJ: Soy lecithin reduces plasma lipoprotein cholesterol and early atherogenesis in hypercholesterolemic monkeys and hamsters: beyond linoleate. Atherosclerosis 1998, 140:147-153.
42. Wilson TA, Nicolosi R, Kotyla T, Sundram K, Kritchevsky D: Different palm oil preparations reduce plasma cholesterol concentrations and aortic cholesterol accumulation compared to coconut oil in hypercholesterolemic hamsters. Journal of Nutritional Biochemistry 2005, 16:633-640.

43. Wilson TA, Nicolosi RJ, Lawton CW, Babiak J: Gender differences in response to a hypercholesterolemic diet in hamsters: effects on plasma lipoprotein cholesterol concentrations and early aortic atherosclerosis. Atherosclerosis 1999, 146:83-91.

44. Ausman LM, Rong N, Nicolosi RJ: Hypocholesterolemic effect of physically refined rice bran oil: studies of cholesterol metabolism and early atherosclerosis in hypercholesterolemic hamsters. J Nutr Biochem 2005, 16:521-529.

45. Nicolosi RJ, Wilson TA, Handelman G, Foxall T, JFK Jr, Vita JA: Decreased aortic early atherosclerosis in hypercholesterolemic hamsters fed oleic acid-rich TriSun oil compared to linoleic acid-rich sunflower oil. J Nutr Biochem 2002, 13:392-402.

46. Ntanios FY, Kooij AJvd, Deckere EAMd, Duchateau GSMJE, Trautwein EA: Effects of various amounts of dietary plant sterol esters on plasma and hepatic sterol concentration and aortic foam cell formation of cholesterol-fed hamsters. Atherosclerosis 2003, 169:41-50

47. Dorfman SE, Wang S, Vega-Lopez S, Jauhiainen M, Lichtenstein AH: Dietary fatty acids and cholesterol differentially modulate HDL cholesterol metabolism in Golden-Syrian hamsters. Journal of Nutrition 2005, 135:492-498.

48. Mitchell PL, Langille MA, Currie DL, McLeod RS: Effect of conjugated linoleic acid isomers on lipoproteins and atherosclerosis in the Syrian Golden hamster. Biochim biophys Acta 2005, 1734:269-276.

49. Cristofori P, Lanzoni A, Gaviraghil G, Turton J, Sbarbati A: Antiatherosclerotic activity of the calcium antagonist lacidipine in cholesterol-fed hamsters. Biomed \& Pharmacother 2000, 54:93-99.

50. Mawatari K, Kakui S, Harada N, Ohnishi T, Niwa Y, Okada K, Takahashi A, Izumi $K$, Nakay Y: Endothelin-1(1-31) levels are increased in atherosclerotic lesions of the thoracic aorta of hypercholesterolemic hamsters. Atherosclerosis 2004, 175:203-212.

51. Kahlon TS, Chow Fl, Irving DW, Sayre RN: Cholesterol response and fatty streak formation in hamsters fed two levels of saturated fat and various levels of cholesterol. Nut Res 1997, 17:1693-1707.

52. Pitman WA, Osgood DP, Smith D, Schaefer EJ, Ordovas JM: The effect of diet and lovastatin on regression of fatty streak lesions and on hepatic and intestinal mRNA levels for the LDI receptor and HMG CoA reductase in F1B hamsters. Atherosclerosis 1998, 138:43-52.

53. Dorfman SE, Lichtenstein AH: Dietary fatty acids differentially modulate messenger RNA abundance of low-density lipoprotein receptor, 3hydroxy-3-methylglutaryl coenzyme A reductase, and microsomal triglyceride transfer protein in Golden-Syrian hamsters. Metabolism: Clinical and Experimental 2006, 55:635-641.

54. Matthan NR, Dillard A, Lecker JL, Ip B, Lichtenstein AH: Effects of dietary palmitoleic acid on plasma lipoprotein profile and aortic cholesterol accumulation are similar to those of other unsaturated fatty acids in the F1B golden Syrian hamster. Journal of Nutrition 2009, 139:215-221.

55. Dorfman SE, Smith DE, Osgood DP, Lichtenstein AH: Study of diet-induced changes in lipoprotein metabolism in two strains of Golden-Syrian hamsters. Journal of Nutrition 2003, 133:4183-4188.

56. Lecker J, Matthan N, Billheimer J, Rader D, Lichtenstein A: Impact of Dietary Fat Type Within the Context of Altered Cholesterol Homeostasis on Cholesterol and Lipoprotein Metabolism in the F1B Hamster. Metabolism 2010, 59:1491-1501.

57. Valeille K, Ferezou J, Parquet M, Amsler G, Gripois D, Quignard-Boulange A, Martin J-C: The Natural Concentration of the Conjugated Linoleic Acid, cis-9,trans-11, in Milk Fat Has Antiatherogenic Effects in Hyperlipidemic Hamsters. J Nutr 2006, 136:1305-1310.

58. Stein $\mathrm{O}$, Dabach $\mathrm{Y}$, Hollander G, Halperin G, Thiery J, Stein Y: Relative resistance of the hamster to aortic atherosclerosis in spite of prolonged vitamin E deficiency and dietary hypercholesterolemia. Putative effect of increased HDL? Biochimica Biophysica Acta 1996, 1299:216-222.

59. Kowala MC, Grove Rl, Aberg G: Inhibitors of angiotensin converting enzyme decrease early atherosclerosis in hyperlipidemic hamsters. Fosinopril reduces plasma cholesterol and captopril inhibits macrophage-foam cell accumulation independently of blood pressure and plasma lipids. Atherosclerosis 1994, 108:61-72. 
60. Surette M, Whelan J, Lu G-P, Broughton K, Kinsella JE: Dependence on dietary cholesterol for $n-3$ polyunsaturated fatty acid-induced changes in plasma cholesterol in the Syrian hamster. J Lipid Res 1992, 33:263-271.

61. McAteer M, Grimsditch D, Vidgeon-Hart M, Benson G, Salter A: Dietary cholesterol reduces lipoprotein lipase activity in the atherosclerosissusceptible Bio F1B hamster. British Journal of Nutrition 2003, 89:341-350.

62. Alexaki A, Wilson T, Atallah M, Handelman G, Nicolosi R: Hamsters Fed Diets High in Saturated Fat Have Increased Cholesterol Accumulation and Cytokine Production in the Aortic Arch Compared with CholesterolFed Hamsters with Moderately Elevated Plasma Non-HDL Cholesterol Concentrations. J Nutr 2004, 134:410-415.

63. Kowala MC, Recce R, Beyer S, Aberg G: Regression of early atherosclerosis in hyperlipidemic hamsters induced by fosinopril and captopril. Journal of Cardiovascular Pharmacology 1995, 25:179-186.

64. Mangiapane EH, McAteer MA, Benson GM, White DA, Salter AM: Modulation of the regression of atherosclerosis in the hamster by dietary lipids: comparison of coconut oil and olive oil. British Journal of Medicine 1999, 82:401-409.

65. Vinson JA, Mandarano MA, Shuta DL, Bagchi M, Bagchi D: Beneficial effects of a novel IH636 grape seed proanthocyanidin extract and a niacinbound chromium in a hamster atherosclerosis model. Mol Cell Biochem 2002, 240:99-103.

66. Vinson JA, Teufel K, Wu N: Red wine, dealcoholized red wine, and especially grape juice, inhibit atherosclerosis in a hamster model. Atherosclerosis 2001, 156:67-72.

67. Lucas EA, Khalil DA, Daggy BP, Arjmandi BH: Ethanol-Extracted Soy Protein Isolate Does Not Modulate Serum Cholesterol in Golden Syrian Hamsters: A Model of Postmenopausal Hypercholesterolemia. J Nutr 2001, 131:211-214

68. Lucas EA, Lightfoot SA, Hammond LJ, Devareddy L, Khalil DA, Daggy BP, Smith BJ, Westcott N, Mocanud V, Soung DY, Arjmandi BH: Flaxseed reduces plasma cholesterol and atherosclerotic lesion formation in ovariectomized Golden Syrian hamsters. Atherosclerosis 2004, 173:223-229.

69. McConihay JA, Horn PS, Woollett LA: Effect of maternal hypercholesterolemia on fetal sterol metabolism in the Golden Syrian hamster. J Lipid Res 2001, 42:1111-1119.

70. Yao L, Horn P, Heubi J, Woollett L: The liver plays a key role in whole body sterol accretion of the neonatal Golden Syrian hamster. Biochimica et Biophysica Acta 2007, 1771:550-557

71. Yao L, Woollett $L$ : Adult sterol metabolism is not affected by a positive sterol balance in the neonatal Golden Syrian hamster. Am J Physiol Regul Integr Comp Physiol 2005, 288:R561-R566.

72. Reeves PG, Nielsen FH, Fahey GCJ: AIN-93 purified diets for laboratory rodents: Final report of the American Institute of Nutrition ad hoc writing committee on the reformulation of the AIN-76A diet. Journal of Nutrition 1993, 123:1939-1951.

73. Turley SD, Spady DK, Dietschy JM: Regulation of Fecal Bile Acid Excretion in Male Golden Syrian Hamsters Fed a Cereal-Based Diet With and Without Added Cholesterol. Hepatology 1997, 25:797-803.

74. Sima A, Stancu C, Constantinescu E, Ologeanu L, Simionescu M: The hyperlipemic hamster - a model for testing the anti-atherogenic effect of amlodipine. J Cell Mol Med 2001, 5:153-162.

75. Lam C, Chen J, Cao Y, Yang L, Wong Y, Ying S, Yeung V, Yao X, Huang Y, Chen Z-Y: Conjugated and non-conjugated octadecaenoic acids affect differently intestinal acyl coenzyme A: Cholesterol acyltransferase activity. Atherosclerosis 2008, 198:85-93.

76. vanTol A, Terpstra A, Berg Pvd, Beynen A: Dietary corn oil versus olive oil enhances HDL protein turnover and lowers HDL cholesterol levels in hamsters. Atherosclerosis 1999, 147:87-94.

77. Terpstra A, Lapre J, Vries Hd, Beynen A: Intact pectin and its polygalacturonic acid regions have similar hypocholesterolemic properties in hybrid F1B hamsters. Nahrung/Food 2002, 46:83-86.

78. Cherng J-Y, Shih M-F: Preventing dyslipidemia by Chlorella pyrenoidosa in rats and hamsters after chronic high fat diet treatment. Life Sciences 2005, 76:3001-3013.

79. Terpstra AH, Holmes JC, Nicolosi R: The hypercholesterolemic effect of dietary soy protein vs. casein in hamsters fed cholesterol-free or cholesterol-enriched semi-purified diets. Journal of Nutrition 1991, 121:371-377.
80. Otto J, Ordovas J, Smith D, Dongen Dv, Nicolosi R, Schaefer E: Lovastatin inhibits diet induced atherosclerosis in FI B Golden Syrian hamsters. Atherosclerosis 1995, 114:19-28.

81. Kassis AN, Marinangeli CP, Jain D, Ebine N, Jones PJ: Lack of effect of sugar cane policosanol on plasma cholesterol in Golden Syrian hamsters. Atherosclerosis 2007, 194:153-158.

82. Krause BR, Bousley RF, Kieft KA, Stanfield RL: Effect of the ACAt inhibitor $\mathrm{Cl}-976$ on plasma cholesterol concentrations and ditribution in hamsters fed zero- and low-cholesterol diets. Clinical Biochemistry 1992, 25:371-377.

83. Kurowska EM, Carroll KK: Hypercholesterolemic responses in rabbits to selected groups of dietary essential amino acids. Journal of Nutrition 1994, 124:364-370.

84. Bensch WR, Gadski RA, Bean JS, Beavers LS, Schmidt RJ, Perry DN, Murphy AT, McClure DB, Eacho PI, Breau AP, Archer RA, Kauffman RF: Effects of LY295427, a Low-Density Lipoprotein (LDL) Receptor UpRegulator, on LDL Receptor Gene Transcription and Cholesterol Metabolism in Normal and Hypercholesterolemic Hamsters. J Pharma Exp Therap 1999, 289:85-92.

85. Lock AL, Horne CAM, Bauman DE, Salter AM: Butter Naturally Enriched in Conjugated Linoleic Acid and Vaccenic Acid Alters Tissue Fatty Acids and Improves the Plasma Lipoprotein Profile in Cholesterol-Fed Hamsters. J Nutr 2005, 135:1934-1939.

86. Rong N, Ausman LA, Nicolosi R: Oryzanol decreases cholesterol absorption and early atherosclerosis in hamsters. Lipids 1997, 32:303-309.

87. Ceryak S, Bouscarel B, Malavolti M, Robins S, Caslow K, Fromm H: Effect of ursodeoxycholic acid on hepatic LDL binding and uptake in dietary hypercholesterolemic hamsters. Atherosclerosis 2000, 153:59-67.

88. Vinson J, Proch J, Bose P, Muchler S, Taffera P, Shuta D, Samman N, Agbor G: Chocolate Is a Powerful ex Vivo and in Vivo Antioxidant, an Antiatherosclerotic Agent in an Animal Model, and a Significant Contributor to Antioxidants in the European and American Diets. J Agric Food Chem 2006, 54:8071-8076.

89. Sanders T, Sandaradura S: The cholesterol-raising effect of coffee in the Syrian hamster. British Journal of Nutrition 1992, 68:431-434.

90. Trautwein E, Forgbert K, Rieckhoff D, Erbersdobler H: Impact of Lcyclodextrin and resistant starch on bile acid metabolism and fecal steroid excretion in regard to their hypolipidemic action in hamsters. Biochimica et Biophysica Acta 1999, 1437:1-12.

91. Lee C-L, Hung H-K, Wang J-J, Pan T-M: Red Mold Dioscorea Has Greater Hypolipidemic and Antiatherosclerotic Effect than Traditional Red Mold Rice and Unfermented Dioscorea in Hamsters. J Agric Food Chem 2007, 55:7162-7169.

92. $\mathrm{Ng} \mathrm{C}$, Yao XQ, Huang Y, Chen Z-Y: Oxidised cholesterol is more hypercholesterolaemic and atherogenic than non-oxidised cholesterol in hamsters. British Journal of Nutrition 2008, 99:749-755.

93. Ginsberg $H$, Kris-Etherton $P$, Dennis B, Elmer P, Ershow A, Lefevre M, Pearson T, Roheim $P$, Ramakrishnan R: Effects of reducing dietary saturated fatty acids on plasma lipids and lipoproteins in healthy subjects: the DELTA Study, protocol 1. Arterioscler Thromb Vasc Biol 1998 18:441-449.

94. Smith D, Ahn Y-S, Pedro-Botet J, Osada J, Mata P, Schaefer E, Ordovas J: Dietary fat saturation distinctly affects apolipoprotein gene expression and high density lipoprotein size distribution in two strains of Golden Syrian hamsters. Nut Res 2001, 21:215-228.

95. Cheema SK, Cornish ML: Bio F1B hamster: a unique animal model with reduced lipoprotein lipase activity to investigate nutrient mediated regulation of lipoprotein metabolism. Nutrition \& Metabolism 2007, 10:27.

96. deSilva P, Davis P, Cheema S: Hyperlipidaemic effect of fish oil in Bio F1B hamsters. British Journal of Nutrition 2004, 91:341-349.

97. Trautwein E, Rieckhoff D, Erbersdobler H: Dietary Inulin Lowers Plasma Cholesterol and Triacylglycerol and Alters Biliary Bile Acid Profile in Hamsters. J Nutr 1998, 128:1937-1943.

98. Meijer GW, Bressers MA, de Groot WA, Rudrum M: Effect of structure and form on the ability of plant sterols to inhibit cholesterol absorption in hamsters. Lipids 2003, 38:713-721.

99. Agbor GA, Vinson JA, Patel S, Patel K, Scarpati J, Shiner D, Wardrop F, Tompkins TA: Effect of Selenium- and Glutathione-Enriched Yeast Supplementation on a Combined Atherosclerosis and Diabetes Hamster Model. J Agric Food Chem 2007, 55:8731-8736. 
100. Faia KL, Davis WP, Marone AJ, Foxall TL: Matrix metalloproteinases and tissue inhibitors of metalloproteinases in hamster aortic atherosclerosis: correlation with in-situ zymography. Atherosclerosis 2002, 160:325-337.

101. Trautwein EA, Liang J, Hayes KC: Plasma Lipoproteins, biliary lipids and bile acid profile differ in various strains of Syrian hamsters mesocricetus auratus. Comp Biochem Physiol 1993, 104A:829-835.

102. Kubow S, Goyette N, Kermasha S, Stewart-Phillip J, Koski K: Vitamin E Inhibits Fish Oil-Induced Hyperlipidemia and Tissue Lipid Peroxidation in Hamsters. Lipids 1996, 31:839-847.

103. Lecker J, Matthan N, Billheimer J, Rader D, Lichtenstein A: Changes in Cholesterol Homeostasis Modify the Response of F1B Hamsters to Dietary Very Long Chain n-3 and n-6 Polyunsaturated Fatty Acids. Manuscript in Preparation 2010.

104. Lu S-C, Un M-H, Huang P-C: A High Cholesterol, (n-3) Polyunsaturated Fatty Acid Diet Induces Hypercholesterolemia More Than a High Cholesterol, (n-6) Polyunsaturated Fatty Acid Diet in Hamsters1. J Nutr 1996, 126:1759-1765.

105. Dillard A, Matthan N, Lichtenstein A: Manuscript in Preparation

106. Daumerie CM, Woollett LA, Dietschy JM: Fatty acids regulate hepatic low density lipoprotein receptor activity through redistribution of intracellular cholesterol pools. Proceedings of the National Academy of Sciences of the United States of America 1992, 89:10797-10801.

107. Tyburczy C, Major C, Lock A, Destaillats F, Lawrence P, Brenna J, Salter A, Bauman D: Individual Trans Octadecenoic Acids and Partially Hydrogenated Vegetable Oil Differentially Affect Hepatic Lipid and Lipoprotein Metabolism in Golden Syrian Hamsters. J Nutr 2009, 139:257-263.

108. Auger C, Laurent N, Laurent C, Besancon P, Caporiccio B, Teissedre P, Rouanet J-M: Hydroxycinnamic acids do not prevent aortic atherosclerosis in hypercholesterolemic golden Syrian hamsters. Life Sciences 2004, 74:2365-2377.

109. Auger C, Rouanet J-M, Vanderlinde R, Bornet A, Deacordea K, Lequeux N, Cristol J-P, Teissedre P-L: Polyphenols-Enriched Chardonnay White Wine and Sparkling Pinot Noir Red Wine Identically Prevent Early Atherosclerosis in Hamsters. J Agric Food Chem 2005, 53:9823-9829.

110. Auger C, Teissedre P-L, Gearain P, Lequeuz N, Bornet A, Serisier S, Besancon P, Caporiccio B, Cristol J-P, Rouanet J-M: Dietary Wine Phenolics Catechin, Quercetin, and Resveratrol Efficiently Protect Hypercholesterolemic Hamsters against Aortic Fatty Streak Accumulation. J Agric Food Chem 2005, 53:2015-2021.

111. Kuksis A: Plasma non-cholestrol sterols. Journal of Chromatography A 2001, 935:203-236.

112. Riss J, Decorde K, Sutra T, Delage M, Baccou J-C, Jouy N, Brune J-P, Oreal H, Cristol J-P, Rouanet J-M: Phycobiliprotein C-Phycocyanin from Spirulina platensis Is Powerfully Responsible for Reducing Oxidative Stress and NADPH Oxidase Expression Induced by an Atherogenic Diet in Hamsters. J Agric Food Chem 2007, 55:7962-7967.

113. Sutra T, Deacordea K, Riss J, Dallas C, Cristol J-P, Rouanet J-M: A Commercial Extract of Fruits and Vegetables, Oxxynea, Acts as a Powerful Antiatherosclerotic Supplement in an Animal Model by Reducing Cholesterolemia, Oxidative Stress, and NADPH Oxidase Expression. J Agric Food Chem 2007, 55:4258-4263.

114. Tarling E, Ryan K, Bennett A, Salter A: Effect of dietary conjugated linoleic acid isomers on lipid metabolism in hamsters fed high-carbohydrate and high-fat diets. British Journal of Nutrition 2008, 101:1630-1638.

115. Schaefer EJ, Lichtenstein AH, Lamon-Fava S, Contois JH, Li Z, Rasmussen $\mathrm{H}_{\text {, }}$ McNamara JR, Ordovas JM: Efficacy of National Cholesterol Education Program Step 2 diet in normolipidemic and hypercholesterolemic middle aged and elderly men and women. Arteriosclerosis \& Thrombosis 1995, 15:1079-1085.

116. Schaefer EJ, Lichtenstein AH, Lamon-Fava S, Contois JH, Li Z, Goldin BR, Rasmussen H, MCNamara JR, Ordovas JM: Effects of National Cholesterol Education Program Step 2 diets relatively high or relatively low in fishderived fatty acids on plasma lipoproteins in middle-aged and elderly subjects. American Journal of Clinical Nutrition 1996, 63:234-241.

117. Martinello F, Soares SM, Franco JJ, Santos AC, Sugohara A, Garcia SB, Curti C, Uyemura SA: Hypolipemic and antioxidant activities from Tamarindus indica L. pulp fruit extract in hypercholesterolemic hamsters. Food and Chemical Toxicology 2006, 44:810-818.
118. Kothari H, Poirier K, Lee W, Satoh Y: Inhibition of cholesterol ester transfer protein by CGS 25159 and changes in lipoproteins in hamsters. Atherosclerosis 1997, 128:59-66.

119. Jia $X$, Ebine $N$, Demonty I, Wang $Y$, Beech $R$, Muise $V$, Fortin $M$, Jones PH: Hypocholesterolaemic effects of plant sterol analogues are independent of ABCG5 and ABCG8 transporter expressions in hamsters. British Journal of Nutrition 2007, 550-555.

120. Cohen B, Matoba N, Mosbach E, McSherry C: Dietary induction of cholesterol gallstones in hamsters from three different sources. Lipids 1989, 24:151-156.

121. Mensink R, Katan M: Effect of dietary fatty acids on serum lipids and lipoproteins. A meta-analysis of 27 trials. Arterioscler. Thromb 1992, 12:911-919.

122. Balk EM, Lichtenstein AH, Chung M, Kupelnick B, Chew P, Lau J: Effects of omega-3 fatty acids on serum markers of cardiovascular disease risk: a systematic review. Atherosclerosis 2006, 189:19-30.

123. Harris WS: $n-3$ fatty acids and serum lipoproteins: animal studies. American Journal of Clinical Nutrition 1997, 65:1611S-1616S.

doi:10.1186/1743-7075-7-89

Cite this article as: Dillard et al:: Use of hamster as a model to study diet-induced atherosclerosis. Nutrition \& Metabolism 2010 7:89.

\section{Submit your next manuscript to BioMed Central and take full advantage of:}

- Convenient online submission

- Thorough peer review

- No space constraints or color figure charges

- Immediate publication on acceptance

- Inclusion in PubMed, CAS, Scopus and Google Scholar

- Research which is freely available for redistribution

Submit your manuscript at www.biomedcentral.com/submit
C) Biomed Central 